\title{
Las historias de García Márquez; su vinculación con los patrones simbólicos y el cambio en la percepción de la realidad a través del contenido metafórico de los relatos
}

\author{
Julieta LEO \\ Universidad de Monterrey. México \\ julieta.leo@udem.edu
}

\begin{abstract}
RESUMEN
En este estudio se pretende descubrir si es posible establecer vínculos entre la teoría científica y la concepción literaria para identificar en qué medida se relacionan los sueños y las historias y si esta relación repercute de algún modo en los receptores. Para este ejercicio se emplearon el cuento "Un señor muy viejo con alas enormes" (1968) de Gabriel García Márquez y el video Losing my religion (1991) del grupo estadounidense REM. A partir del análisis y las observaciones hechas para este estudio, se expone que el ser humano tiene la capacidad para acceder a un estado de trance y que otros pueden emplear técnicas para hacerlos entrar en él. Se plantea que más allá de las imágenes que crea o se le presentan al sujeto, existe la posibilidad de completar los propios patrones simbólicos para adquirir otra perspectiva de la realidad.
\end{abstract}

Palabras clave: sueños, realismo mágico, hipnosis, García Márquez, patrones simbólicos.

García Márquez's stories; their connection to symbolic patterns and changes in the perception of reality through the metaphoric content of his tales

\begin{abstract}
This study attempts to discover and establish connections between scientific theory and literary perception to identify the degree to which dreams and stories are related to each other and if this relationship has some effect on receptors. For this exercise, the story "A Very Old Man with Enormous Wings" ("Un señor muy viejo con alas enormes") (1978) by Gabriel García Márquez and the video Losing My Religion (1991) by the U.S. rock band REM were used. From the analysis and observations made for this study, it is found that humans have the ability to enter into a trance state and it is suggested that beyond the images that are created or presented to subjects, there is the possibility of completing one's own symbolic patterns to acquire another perspective of reality.
\end{abstract}

Key words: dreams, magical realism, hypnosis, García Márquez, symbolic patterns. 
SUMARIO: I.Introducción. 2.Lo mágico y el estado REM. 3.¿Ficción o realidad con sentido metafórico?: "Un señor muy viejo con unas alas enormes" y Losing my religion. 4.Conclusiones. 5.Bibliografía.

\section{Introducción}

Si se considera que los sueños transcurren en un tiempo no determinado por la sucesión cronológica y se expanden en un espacio de múltiples dimensiones para manifestarse en un lenguaje de imágenes significativas, se puede decir que existe parecido entre éstos y el proceso del pensamiento creativo.

Por lo antes mencionado - sin que la intención sea confundir el territorio de lo onírico con las letras - me interesa indagar 1) si es posible establecer vínculos entre la teoría científica y la concepción literaria, o la creación artística. 2) En qué medida sueños e historias se relacionan, 3) y si esta relación repercute de algún modo en los receptores.

El estudio parte del concepto de García Márquez sobre la escritura de ficción como un acto hipnótico, y se explora a la luz de las investigaciones sobre el sueño de Joe Griffin. ${ }^{1}$ Como ejercicio retórico — sobre cuyos sondeos se sustenta la hipótesis - se cotejan el cuento "Un señor muy viejo con unas alas enormes" (1968) y el video Losing my religion (1991) del grupo estadounidense REM.

Particularmente, me interesa aproximarme a la génesis del proceso creativo de García Márquez, adentrarme en la magia de sus relatos para mostrar esa narración inmutable, herencia de la abuela Tranquilina y la tía Francisca, que "se convertiría en un tono o estilo, definido como la capacidad de hacer creíble lo increíble [...] de percibir o representar lo insólito convirtiéndolo en materia cotidiana" (Ulchur 2006: 256).

Antes de continuar necesito hacer dos aclaraciones. En primer lugar, admito que incursionar en dominios del Realismo Mágico (RM) requiere una delimitación muy precisa, ya que son muchas y muy controvertidas las cuestiones ligadas al término. En mi caso, la delimitación vino de la observación de una de las peculiaridades - a mi juicio - más significativas que se asocian al término: la "técnica" para contar historias que el mismo autor proporciona. Por consiguiente, "la cara de palo" de la abuela Tranquilina, su modo de percibir la realidad y de comunicarla, es ineludible para iniciar el acercamiento teórico al proyecto estético de [los textos] García Márquez (Araujo Fontalvo, Orlando). Mi objetivo en este punto no es aportar una

${ }^{1}$ El investigador explica - entre otras cosas - porqué soñar despierto es y ha sido fundamental para el desarrollo humano, y porqué las historias y las metáforas son universalmente atractivas. Naturalmente que abordo su trabajo en forma selectiva, esto es, considerando concretamente los aspectos que dan soporte a lo que planteo. 
teoría más; al contrario trato de encontrar una aproximación para describir manifestaciones literarias que se resisten a cualquier tipo de clasificación.

$\mathrm{Y}$ en segundo lugar, al valorar su visión subjetiva no intento hacer la apología de un acercamiento arbitrario o anárquico: es un asunto de ideales; de visión del mundo.

Finalmente, el éxito de sus obras, en cuanto a la intención hipnótica que persigue no se ha documentado, pero su impacto en la imaginación de los lectores ha dejado considerables huellas que trascienden hasta el día de hoy. Un dato suficiente -me parece-para pasar a la exposición.

\section{Lo mágico y el estado REM}

Gabriel, un ángel caído del cielo (Harss: 389)

La construcción de sueños es semejante a la construcción literaria que pertenece al contexto del RM, ya que de acuerdo a los estudiosos del tema, cuando se lee una obra inscrita en el ámbito de este término se admite que la narración "descarta el organismo de defensa intelectual, suspende el juicio hasta la insipiencia deliberada, o se abstiene en cualquier caso de valorar e interpretar la realidad" (Llarena 1997: 113). ${ }^{2}$ Dicho acontecimiento puede ser comparado con el proceso onírico durante el cual, según Rosalind Cartwright, "aceptamos el imaginario como real [y] usualmente no reconocemos que nuestros sueños en realidad son eventos fantasiados" (Cartwright: 1)."3

En la conceptualización de una y otra perspectiva se vislumbra un elemento en común: la imposibilidad de cuestionamiento ante hechos insólitos que acontecen bajo cualquier circunstancia. El postulado me recuerda lo que ha señalado García Márquez:

La escritura de ficción es un acto hipnótico, uno trata de hipnotizar al lector para que no piense sino en el cuento que tú le estas contando y eso requiere de una enorme cantidad de clavos y tornillos y bisagras para que no despierte. Eso es lo que llamamos la carpintería, esa es la técnica de contar, esa es la técnica de escribir o la técnica de hacer una película. [...]. Cuando uno atrapa a un lector

${ }^{2}$ Aquí se requiere otra observación: considerando que la definición del RM y el corpus literario que la constituye se condicionan deductiva e inductivamente, me parece importante partir de una definición claramente expuesta para hacer posible un diálogo intersubjetivo.

3 Dice la experta: "Dreams are hallucinations that occur in sleep. They are normal hallucinations in that they are sensory images, mostly visual but auditory and other sensations also are experienced, that we believe to be real at the time but are not actually happening. They have a story-like structure. "http://rosalindcartwright.com/faqs/" 
logra comunicarle un ritmo respiratorio que no se puede romper, porque si se rompe despierta. ${ }^{4}$

$\mathrm{Su}$ "técnica" se refuerza $-\mathrm{y}$ adquiere otro matiz- si se consideran las investigaciones de Joe Griffin. ${ }^{5}$ Siguiendo la línea de la investigación priorizo aspectos y no ingreso, por el momento, en terrenos del psicoanálisis, ni la psicoterapia. Me concentro en sus descubrimientos sobre el estado REM, por ser los que incumben al contexto de mi argumentación. ${ }^{6}$

En su afán por resolver uno de los enigmas (más antiguos) de la naturaleza humana y sus implicaciones, esto es por qué soñamos, Griffin aporta una teoría que es consistente con los hechos biológicos del soñar y brinda, al mismo tiempo, una explicación del porqué ocurre el simbolismo en los sueños (Griffin 2006: 69). Concuerda con Freud en que los sueños tienen un significado latente, pero difiere en el origen, ya que para Griffin éste se encuentra en las expectativas conscientes, y no en los impulsos inconscientes infantiles. Según Griffin los sueños no son deseos insatisfechos, sino analogías sensoriales y metafóricas, patrones que surgen de nuestras memorias de lo no expresado emocionalmente durante el día. Basado en sus estudios y la investigación de las recientes décadas descubrió que soñar está íntimamente asociado con el estado REM. ${ }^{7}$

4 “La escritura embrujada. Documental dedicado a Gabriel García Márquez". Letrarte (9 de enero 2012) Recuperado el 22 de diciembre de 2013 de

http://letrarteforca.blogspot.mx/2012/01/la-escritura-embrujada-documental.html

${ }^{5}$ Joe Griffin es psicólogo e investigador graduado en la London School of Economics. Experto en la práctica psicoterapéutica así como en la formación de psicoterapeutas y de gran influencia en el mundo de la psicoterapia. Griffin trabaja con Ivan Tyrrell, en psicología y comportamiento humano. Sus investigaciones se centran en la eficacia de otro tipo de intervenciones psicológicas utilizadas por psicoterapeutas y orientadores, su enfoque ha demostrado ser de enorme utilidad en la práctica y ahora es utilizado por una amplia gama de profesionales de la salud, así como en educación, trabajo social, negocios e incluso diplomacia. Griffin es ampliamente reconocido como uno de los oradores más preparados en psicología y comportamiento humano y ha sido consultor de psicólogos y colaborador de dos series de TV (BBC y LWT). También regularmente aparece en la radio, tanto en Irlanda y el Reino Unido (incluyendo la BBC Radio) ha sido entrevistado por numerosas publicaciones, incluyendo el New Scientist, Financial Times y el Washington Times. Es coautor, con Ivan Tyrrell de numerosos libros y publicaciones y es miembro de la Junta Editorial de la revista Givens Human. Joe vive en Irlanda con su esposa y su familia. "http://why-we-dream.com/joe-griffin.htm"

${ }^{6}$ Remito a los interesados a su libro dreaming reality en donde se ofrece una prolija explicación.

${ }^{7}$ REM es la etapa del sueño en que la actividad neurológica es similar a la que se tiene cuando se está alerta, inclusive llegando a tener movimientos oculares rápidos (REM por sus siglas en inglés, rapid eye movement) con los que pareciera que la persona se encuentra 
Uno de sus hallazgos más fructíferos fue encontrar que este estado puede activarse fuera del sueño, en momentos como el "soñar despierto", los estados psicóticos y la hipnosis (Griffin 2006: 45). Explica que todos entramos en "trance", muchas veces al día sin darnos cuenta y demuestra que esto se vincula con el estado REM. Un trance - dice- es un estado de atención enfocado, alguien absorto ${ }^{8}$ por ejemplo al escuchar a un orador, al tratar de resolver un problema, o durante una actividad que requiere precisión exacta; sin embargo, el trance que no pasa desapercibido y se admite, en algunos casos, como algo místico es el estado de hipnosis.

No hace mucho los hipnotistas eran vistos como magos con poderes ocultos, y han mostrado su habilidad para hacer que las personas se comporten de manera extraordinaria o ridícula, haciéndolos ver y oír cosas que no están ahí. Evidentemente no tienen poderes sobrenaturales, pero sí la facultad para echar a andar la maquinaria del estado REM. Lo que sucede, en este caso, es que en lugar de que sean los impulsos de memoria e instintos personales los que provean "el guión", es el hipnotista quien lo hace. Trataré de explicar.

De acuerdo a las investigaciones de Griffin, el estado REM es como un teatro en el que el sueño toma lugar, pero el guión del sueño está separado del teatro (Griffin, 2006: 142). Es decir, el estado REM es nuestro propio generador de realidad y el guión del sueño actúa o se hace real dentro de éste. En cambio, la audiencia del hipnotista observa la actuación de guiones sugeridos por él a los voluntarios (que han sido puestos en estado REM). Esta situación es casi idéntica al modo en como un pensamiento en la vigilia se transforma metafóricamente en una realidad en el sueño. Por eso se acepta que la hipnosis es un medio para acceder al teatro del estado REM que, como un generador de realidad, viste nuestras introspecciones con ropa sensorial metafórica y las hace actuar como sueños. Es así como se enuncia, por primera vez, una teoría que separa el contenido del sueño del estado mental en el que el sueño ocurre. Conviene añadir que el guión está ligado a lo que Griffin denomina la «lógica del trance»(Griffin 2006: 147). Por lógica del trance se entenderá cuando el individuo, en un sueño o estado de hipnosis, hace algo que le parece normal, aunque sea completamente absurdo. Por ejemplo, conversar con un muerto sabiendo que lo está sin que le cause conflicto.

En síntesis, Griffin asegura que la cultura no pudo desplegarse sin que la humanidad aprendiera a ingresar al estado REM mientras se está despierto y conscientemente se sueña. Señala que el mecanismo que detona la creatividad desde

despierta pero con los párpados cerrados (Corsi 1983: 54). En esta etapa es donde se presentan los sueños más vívidos.

8 “pasmado, entregado a la meditación, contemplación" (DRAE). 
sus orígenes es el mismo que se usa en el pensamiento de hoy. ${ }^{9}$ Insiste en que la metáfora es un componente esencial de la creatividad; lo que aparece en un lienzo o pantalla es la metáfora del artista (que representa otro aspecto de la realidad), mientras el escritor, al evocar situaciones o experiencias, crea circunstancias con las cuales un lector puede sentir empatía, y aprender a ver su realidad desde otra perspectiva (Griffin 2006: 152). Infiere que la metáfora es clave para la dimensión científica al igual que las creaciones artísticas. ${ }^{10}$

Así pues, cuando se muestra que los fenómenos que se manifiestan al estar hipnotizado son los mismos que ocurren en estado REM, "la técnica" de García Márquez adquiere otro matiz. Veamos ahora cómo se manifiesta en el cuento.

\section{¿Ficción o realidad con sentido metafórico?: "Un señor muy viejo con unas alas enormes" y Losing my religion}

Una pesadilla es algo de lo que puedes despertar [...]. Pero los pensamientos y las ideas que permanecen después de que tus terrores hayan desaparecido son algo bastante peor

(Katzenbach: 45)

${ }^{9}$ Como hemos visto cuando que alguien obtiene una nueva idea que viene a ellos después de un prolongado esfuerzo por resolverlo, el esfuerzo es un ingrediente necesario para enfocar al cerebro, pero cuando la persona se relaja de esta lucha y se adentra en el estado REM, quizá soñando despierto mientras toma un paseo, por ejemplo, es que la nueva idea viene a su mente. Esto es porque hacer conexiones metafóricas corresponde a la parte derecha del cerebro, sin embargo, el lóbulo derecho necesita la dirección de la parte analítica que es la izquierda.

${ }^{10}$ La metáfora no se emplea como dispositivo dramático que resalta principios o conceptos como en la creación de una obra de arte, es, más bien, la traducción del despertar de una preocupación en un escenario sensorial análogo: el sueño. (Griffin, 2006: 26)

11 "Las investigaciones neurofisiológicas sobre el sueño, desarrolladas en Francia a partir de 1959, demuestran que sus procesos están estrechamente vinculados con la acción cortical. El neurofisiólogo Michel Jouvet ha demostrado que cuando una persona duerme y sueña, el movimiento ocular se acelera y el electroencefalograma muestra una actividad cortical es decir, inteligente, que puede llegar a ser más intensa que en el estado de vigilia. Estas experiencias han sido también confirmadas por el director del laboratorio de neurobiología de Massachussets, A. J. Hobson. Por ser un sueño en el que la actividad consciente se manifiesta, es llamado "sueño paradojal". Las experiencias psicofisiológicas de la tomografía por emisión de positrones (TEP) confirman la realidad de los procesos oníricos y, superando la teoría freudiana, muestran que existe un caso particular de consciencia del subconsciente." Véase Helios Jaime. "Psicofisiología e ideosemática del sueño". Neuro ciencia cultura. http://pacotraver.wordpress.com/psicofisiologia-eideosemantica-del-sueno/ 
El realismo mágico, como híbrido entre lo irreal y lo cotidiano, provee la base para contextualizar "Un señor muy viejo con unas alas enormes" (1968), si se considera que - al menos en el cuento- el hecho de encontrar un hombre alado no genera significativas sorpresas entre los habitantes del pueblo, y su llegada se reduce a un evento fútil e indigno para la jerarquía de quien parece evocar a un ser angelical. Elisenda y Pelayo se asombran cuando encuentran en su patio al hombre viejo que [...] "no podía levantarse porque se lo impedían sus enormes alas, [pero] se sobrepusieron muy pronto [...] pasaron por alto el inconveniente de las alas, y concluyeron $[\ldots]$ que era un náufrago solitario de alguna nave extranjera abatida por el temporal" (García Márquez 2012: 5-6).

García Márquez ha construido esta historia y el lector asume ese rol pasivoactivo en el que no pregunta. Sin embargo, al salir de la ensoñación no queda exento de sentir curiosidad por deslindar una ficción mágica de una realidad con contenido metafórico (Menton 1998: 38). ${ }^{12}$ Entonces (bajo riesgo de enfrentarse con el dialecto hermético del ser alado) podría preguntarse, entre otras cosas: ¿nos quiere decir algo al elegir a un ángel decrépito como protagonista?

La relación entre el cuento y el video ${ }^{13}$ puede cifrarse desde múltiples perspectivas. Una primera identificación muestra lazos obvios como la figura del ángel y la exhibición del mismo bajo los reflectores, aunque existen otros aspectos que apuntan a estudios más detallados como el tema del culto religioso.

Ahora bien, si la música y el video ${ }^{14}$ se enfocan desde el punto de vista de la ensoñación, podría decirse que cumplen la condición establecida por García Márquez en cuanto a su modo de estructurar una obra. Veamos por qué.

Primero. En la canción destaca el ostinato ${ }^{15}$ de la mandolina. Esto recuerda lo que refiere Michael Harner sobre los chamanes y el empleo del tambor "para alcanzar una realidad no ordinaria". Dice Harner: "en la Unión Soviética descubrí que los auténticos chamanes [...] emplean exclusivamente el tambor. [...] el sonido simple y monótono de los golpes del tambor constituye el vehículo más común del

${ }^{12}$ Al respecto Menton cita el estudio de Patricia Merivale sobre Midnigth's Children de Salman Rushide: "[...] los juegos que hacen los magos de Delhi con la ilusión, todos sugieren en su contexto que 'la realidad puede tener un contenido metafórico; eso no la hace menos real' (Rushdie: 200), sino en términos del realismo mágico más real...Los magos, como Saleem [el narrador] doblan la realidad sin olvidar jamás lo que es. Ellos también son mágicorrealistas y por lo tanto, obviamente artistas" (Merivale: 338-339).

${ }^{13}$ Incluida en su álbum Out of Time de 1991.

${ }^{14}$ El video fue un éxito e incluso ganó el premio de "Video del Año" en los MTV Video Music Awards (1991).

${ }^{15}$ De acuerdo al Diccionario Harvard de Música: Figura melódica y/o rítmica, repetida persistentemente en toda una composición o en alguna sección de la composición (366). Véase Randel, Don Michael. Diccionario Harvard de Música México: Diana, 1996. El ostinato de la mandolina fue compuesto por el guitarrista del grupo: Peter Buck. 
viaje chamánico, y no los productos psicodélicos." (Doore 2006: 31-33). Tenemos ahí un ritmo inquebrantable. Debo señalar que Griffin dedica un apartado a los chamanes (Grifin 2006: 207), lo destaco porque más adelante volveré a mencionarlos.

Segundo. Si se presta atención al video dirigido por Tarsem Singh, no es difícil relacionarlo con un sueño y lo que sucede en éste, pues observamos sin cuestionar una red de correspondencias y analogías que proyectan lo real en lo imaginario. En la secuencia de la interpretación se intercalan imágenes que no corresponden ni interfieren con ésta. Los integrantes se desplazan por una habitación. Una ventana abierta permite ver que llueve, del alféizar una jarra con leche cae estrellándose contra el piso; la canción inicia y las imágenes se entreveran: religión, milicia, personajes de oriente. Más adelante el viejo con alas cae ante un ángel de alas doradas; vemos planos, chispas, pinturas vivientes (tableaux vivant) ${ }^{16}$ y entre éstas y otras imágenes, sin alterar la armonía ni romper el ritmo, la figura convulsiva de Michel Stipe — cantante y protagonista del video - cuya intención, por virtud de la letra, tratamos de interpretar. ${ }^{17}$

Hay quien relaciona la letra con el amor, lo que viene a ser de interés reflexivo porque es un tanto mágica la etapa del enamoramiento. No obstante, para David Bukley, es una metáfora de la fama de Stipe; seducido por ella tiene que pagar el precio: la pérdida de privacidad e identidad. "Perder tu religión" de hecho significa perder los estribos, salirte de quicio, es una expresión sureña que incluso los integrantes del grupo consideraban oscura. ${ }^{18}$

Se muestra que los acontecimientos del video podrían tener un significado más allá del contenido manifiesto de la historia. El título en sí mismo es un ejemplo: "Perdiendo mi religión" es la traducción textual. Y, aunque puede asociarse con el conjunto de creencias o dogmas acerca de la divinidad, también podría cifrar otro mensaje; la religión como el amor son tópicos que ordinariamente no son fáciles de cuestionar por el temor a descubrir lo que implican sus constructos. ${ }^{19}$

Se establece la analogía de la vigilia y el sueño, el momento en el que el soñador despierta y asume que las imágenes son parte de algo inexplicable pero innegable

${ }^{16}$ De Caravaggio El santo entierro (1602-1604), La incredulidad de Santo Tomás (1602) y San Sebastián (1525) de Giovanni Antonio Bazzi.

${ }^{17}$ Stipe told Rolling Stone magazine: "I wanted to write a classic obsession song. So I did." In addition to calling it a song about "obsession," Stipe has also referred to it as a song about "unrequited love" in which all actions and words of the object of your obsession are scrubbed for hidden meaning and hopeful signs. The lyrics pretty clearly support this: "I thought that I heard you laughing, I thought that I heard you sing. I think I thought I saw you try." (thanks, Redstar-Redding, CT). "http://www.songfacts.com/detail.php?id=1256"

18 Véase David Buckley.

19 2. m. Psicol. Categoría descriptiva bipolar con la que cada individuo organiza datos y experiencias de su mundo, como el frío y el calor, lo dinámico y lo estático, etc. (DRAE). 
porque lo sintió, estuvo ahí y por ende tuvo que vivirlo en algún fragmento de su realidad. Así, en el video se ven las alas del ángel mucho antes de que caiga, lo que podría revelar que existió en la realidad del cantante. Pero por otro lado, quizás represente sólo un sueño, como lo indica el final de la canción. ${ }^{20}$ Sobre esto último tengo interés en subrayar dos cosas.

Primera, Singh reconoce la influencia de Tarkovsky, el cineasta que enfrentó, de acuerdo a sus palabras "la necesidad de filmar sueños" (Tarkovsky, 1991:33). Segunda, se admite que el cuento de García Márquez inspiró el video, ${ }^{21}$ pero, hasta donde se sabe el cuento refiere una historia, no un sueño. Algo que llama la atención es el hecho de que la letra de la canción, compuesta por Stipe, no coincide con el argumento del cuento elegido por Singh para elaborar el video. Sin embargo, como se mencionó, existe un vínculo entre los sueños y las historias que se inscriben en el RM. Surge la pregunta ¿conocía Singh esta relación? Pensemos que sí. En todo caso, lo que sorprende es otro asunto.

El grupo elige a un director de video que se inspira en el cuento de un escritor que pretende hipnotizar al lector. ${ }^{22}$ Años más tarde (15 para ser exactos) ${ }^{23}$ un investigador expone una teoría que señala al trance hipnótico como una forma de acceder al estado REM, y lo considera "uno de los logros más importantes de los últimos tiempos" (Griffin 2006: 149). ${ }^{24}$ Si se toman en cuenta los años transcurridos y las diferentes profesiones e intereses de los involucrados, resulta extraño que el nombre del grupo sea el mismo que denomina esta fase del sueño. Extenderme sobre el asunto sobrepasa los límites establecidos, así que me abstengo de valorar o interpretar y lo acepto como una simple casualidad. Dejo pendientes el nombre del grupo y el hecho de que la canción sea parte del álbum Out of Time. La relación puede ser evidente; pero tal vez no sea así.

Es importante destacar que de acuerdo a Griffin, los cuentos trabajan de manera alineada con el modo en que trabaja nuestro cerebro. Cualquier buen cuento o

20 "But that was just a dream, try, cry, why, try / That was just a dream, just a dream, just a dream. Dream".

${ }^{21}$ Véase Massimo Cotto.

22 "Hemos visto que acceder al estado REM fuera del sueño es el mecanismo que utilizamos para la transmisión de la cultura, lo que significa que cualquier persona que nos enseñe algo está enfocando nuestra atención y poniéndonos en un estado de hipnosis" (Griffin 2006: 151).

${ }^{23}$ El video es presentado en 1991 y el grupo nace en 1980, Stipe elige el nombre: REM, aludiendo a la fase del sueño. Surge otra duda ¿conocía Singh los estudios de Griffin, específicamente los que conciernen a los cuentos o historias y esta fase del sueño? Aunque pensemos que sí, la publicación del libro se hace en 2006, esto es, 15 años después de crear el video.

${ }^{24}$ REM es el estado natural para reprogramar a nuestros cerebros, así que aunque la hipnosis puede usarse para beneficiar también puede ser peligrosa (Griffin 2006:147). 
historia, asegura, puede ampliar nuestro panorama al darnos otra visión para comprender situaciones de la vida. La razón por la que nos iluminan es porque emplean el mismo proceso que la naturaleza para la transmisión de conocimiento. ${ }^{25}$

Una última observación para complementar este punto. Griffin señala que la clave del aprendizaje en los niños tiene lugar cuando entran en estado REM, por corto que sea el periodo, para vincular nueva información al patrón de significado que ya existe en su mente. Asegura que los adultos que continúan haciendo esto, incluso en edad avanzada, se convierten en los más sabios de entre nosotros (Griffin 2006:151-152). Recordemos las palabras de García Márquez para aplicarlas a lo que señala Griffin: "Cuando uno se concentra absorbe todo como una esponja. Cuando me di cuenta de eso hice dos años -el cuarto y el quinto- con calificaciones máximas en todo. Me exhibían como un genio [...] y a nadie le pasaba por la cabeza que eso yo lo hacía para no tener que estudiar y seguir metido en mis asuntos" (García Márquez, Para contar historias, 2). Luego nos cuenta: "cuando estoy escribiendo una novela me atrinchero en mi mundo y no comparto nada con nadie. Soy de una arrogancia, una prepotencia y una vanidad absolutas. ¿Por qué? Porque creo que es la única manera que tengo de proteger al feto, de garantizar que se desarrolle como lo concebí" (García Márquez, Para contar historias, 3 )

\section{Conclusiones}

Más que una experiencia estética fue un trance místico, una revaloración instantánea del mundo, de la continuidad del mundo (Pitol: 80).

En conclusión. Me interesa dejar claro que la epistemología no ha sido inmolada por la inclusión de la experiencia subjetiva, y que se atiende la información objetiva empírica. Mis observaciones, de ninguna manera pretenden ser definitivas o esencialmente correctas. Lo expuesto refiere la capacidad del ser humano para acceder a un estado de trance, ${ }^{26}$ y las técnicas de otros para hacerlo entrar en éste.

${ }^{25}$ Como se explicó, la naturaleza a través del estado REM proporciona un patrón, pero éste es solo un patrón parcial que aún no ha encontrado su "cuento" en el ambiente externo para completarlo (Griffin 2006:159). El estado REM es un mecanismo que nos conecta con la realidad; está siempre activo buscando los códigos necesarios para empatar metafóricamente cualquier cosa significativa en el medio ambiente (Griffin 2006:190).

26 "Todos nacemos con una rica herencia natural -una mente parcialmente formada que contiene un tesoro genético de los patrones de conocimiento innato. Estos patrones aparecen como necesidades físicas y emocionales que deben cumplirse para que nuestras mentes deben desplegarse y desarrollarse a su máximo potencial. ¿Qué tan bien se conectan? desarrollarse y enriquecerse con el mundo determina nuestro propio carácter particular, nuestra claridad de percepción y nuestra propia salud física y emocional de nuestra familia y la felicidad -, así como la madurez de la sociedad en general que creamos a nuestro 
Se plantea que más allá de las imágenes — que crea o se le presentan — existe la posibilidad de completar los propios patrones simbólicos para adquirir otra perspectiva de la realidad. ${ }^{27}$

Como señala Italo Calvino en sus propuestas para este milenio, "el chamán [anulaba] el peso de su cuerpo, transportándose en vuelo a otro mundo, a otro nivel de percepción donde podía encontrar fuerzas para modificar la realidad [...] No me parece forzado conectar esa función chamánica o de hechicería documentada por la etnología y el folclore, con lo imaginario literario; por el contrario, creo que la racionalidad más profunda implícita en toda labor literaria debe buscarse en las necesidades antropológicas a las que aquella corresponde" (Calvino 2000: 41-42). ${ }^{28}$

Este es el punto que suscita uno de los objetivos de mi estudio: el hecho de que la carpintería de García Márquez promete el acceso a otro nivel de percepción. Sus relatos están permeados de «magia» que no se debe dejar disolver. Como dijo Calvino: en "El universo infinito de la literatura se abren siempre otras vías que explorar $[\ldots]$ estilos o formas que pueden cambiar nuestra imagen del mundo" (Calvino 2000:23).

alrededor. Además de las necesidades emocionales, la naturaleza nos ha dado una serie de recursos para ayudarnos a satisfacer esas necesidades en cualquier ambiente que nos encontramos. La depresión es causada generalmente por preocuparse de las necesidades no satisfechas - las necesidades de control, de seguridad, de significado, para la intimidad, la conexión a la comunidad en general, etc - y por el mal uso de algunos de los recursos innatos. La preocupación, por ejemplo, es un mal uso de uno de nuestros recursos innatos más poderosos, el de la imaginación.” Entrevista a Joe Griffin. New Scientist, 2003.

27 "También utilizamos la metáfora y la narración de cuentos. La gente está acostumbrada a escuchar historias y anécdotas que lo reconfortan. Una metáfora apropiada, que figure en una historia, puede hacer pasar por alto la actitud defensiva de la mente consciente e ir como una semilla a la corteza cerebral derecha, la cual contiene los patrones. Más tarde, cuando recuerda la terapia, el patrón en la neocorteza derecha dispara y hace las conexiones de forma espontánea, surge un "¡Ajá!". Pueden entonces "apropiarse" de la visión, y es más fácil para ellos trabajar así. He aquí un ejemplo. Un paciente anciano estaba deprimido por ser incontinente. Un colega comenzó a hablarle de su tío y su tía, que tenía una preciosa casa donde parte de la familia vivía y todo el mundo amaba. Él mismo solía ir allí a menudo como un niño. Y luego, poco a poco comenzó a introducir la metáfora -que a medida que crecía la casa, había algunas manchas de humedad y los problemas de plomería, pero a nadie parecía importarle, todo el mundo amaba la vieja casa y seguían trayendo a sus familias y sus amigos allí. El salió de su depresión sin saber que había tenido ayuda. Esto se debe a que su cerebro había absorbido un patrón más grande (metafórico) que podía reemplazar el que lo había presionado". "Entrevista a Joe Griffin". New Scientist, 2003.

${ }^{28}$ La antropología es el "Estudio de la realidad humana [la] Ciencia que trata de los aspectos biológicos y sociales del hombre" (DRAE). 
Resulta estimulante recordar a Sergio Pitol y pensar en trocar "una experiencia estética en un trance místico" (Pitol 2000: 80). No obstante, al final, y como siempre, el lector tiene la última palabra, el mismo García Márquez declaró sobre sus cuentos: "El que los lea sabrá qué hacer con ellos" (García Márquez 2012:350).

\section{BIBLIOGRAFÍA}

ANDERSON, Imbert.

1976 El realismo mágico en la ficción hispanoamericana. El realismo mágico y otros ensayos. Caracas: Monte Ávila Editores.

BETTELHEIM, Bruno.

1994 Psicoanálisis del cuento de hadas. Barcelona: Grijalbo-Mondadori. BLACK, Johnny.

2004 Reveal: The Story of R.E.M. Backbeat Books. BUCKLEY, David.

2001 R.E.M.: Fiction: An Alternative Biography. London: Virgin Books Bukatman, Scot.

BRAVO, Víctor.

1991 Magias y maravillas en el continente literario. Caracas: Ediciones de la casa de Bello.

CALVINO, Italo.

$2000 S$ eis propuestas para el próximo milenio. Madrid: Siruela.

CotTo, Massimo.

2009 We will rock you. Segreti e bugie. 709 canzoni come non le avete mai sentite. Milano: RCS.

CORSI, María.

1983 Psicofisiología del sueño. México: Trillas.

COBIÁN MENA, Alberto.

2004 La hipnosis y sus aplicaciones terapéuticas. Barcelona: Morales I Torres.

DOORE, Jean Gary (ed.).

2006 “Qué es un chamán? Tambores, drogas y ECC”, en El viaje del chamán. México: Editorial Kairos..

ELIADE, Mircea.

2009 El chamanismo y las técnicas arcaicas del éxtasis. México: FCE.

FONTALVO ARAUJO, Orlando.

2006 El hábito de García Márquez. Disponible en:

http://www.ucm.es/info/especulo/numero25/habitus.html.

FRAME, Tom. 
2009 Loosing My Religion: Unbelief in Australia. Sidney: UNSW.

FEIXAS, Guillem.

2008 "Hipnosis y terapias cognitivas", Apuntes de psicología, $n^{\circ} 26$, disponible en:

http://www.cop.es/delegaci/andocci/files/contenidos/vol_26_2_4. pdf

GARCÍA USTA, Jorge.

1995 Cómo aprendió a escribir García Márquez. Medellín, Colombia: Editorial Lealon.

GARCÍA MÁRQUEZ, Gabriel.

2012 "Un señor muy viejo con unas alas enormes", en La increíble y triste historia de la cándida Eréndira y de su abuela desalmada. México: Diana.

2012 "Prólogo. Porqué doce, porqué cuentos y porqué peregrinos", en Todos los cuentos. México: Diana.

2010 Obra periodística 5 notas de prensa 1961-1984. México: Diana.

s/f Para contar historias. ARCHIVO CHILE, Web del Centro Estudios "Miguel Enríquez", CEME: http://www.archivo-chile.com

GRIFFIN, Joe y Ivan TYRREL.

2006 dreaming reality. Great Britain: The bath Press.

GIARDINELLI, Mempo.

1998 El cuento como género literario en América Latina. Ceremonia de Premiación del Premio Centroamericano de Literatura "Rogelio Sinán" 1997-1998, Auditorio de la Lotería Nacional de Beneficencia.

HARSS, Luis.

1975 Gabriel García Márquez o la cuerda floja”, en Los nuestros. Buenos Aires: Editorial Sudamericana.

JOUVET, Michel.

1999 The Paradox of Sleep: The Story of Dreaming. London: MIT Press. KATZENCACH, John.

2009 La historia del loco. Barcelona: Ediciones B.

LLARENA, Alicia.

1997 "Un balance crítico: la polémica del realismo mágico y lo real maravilloso americano", Anales de literatura Hispanoamericana, $\mathrm{n}^{\circ} 26$, pp. 107-117.

LEVI-STRAUSS, Claude.

2002 Claude. Mito y significado. Madrid: Alianza Editorial.

MENTON, Seymour.

2003 Historia verdadera del realismo mágico. México: FCE.

2003 El cuento hispanoamericano. México: FCE.

2002 Caminata por la narrativa latinoamericana. México: FCE. 
MENA, Lucila.

1975 "Hacia una formulación teórica del realismo mágico", Bulletin Hispanique, Vol. 77.

PALENCIA-ROTH, Michael.

1983 Gabriel García Márquez: la línea, el círculo y las metamorfosis del mito. Madrid: Gredos.

PITOL, Sergio.

2000 El viaje. México: Ediciones Era.

RANDEL, Don Michel.

1996 Diccionario Harvard de Música. México: Diana.

SAMPER, María Elvira.

1989 "Entrevista a García Márquez”, Semana, 358, Bogotá.

TARKOVSKY, Andrey.

1989 Esculpir el tiempo. México: Ediciones Rialp.

UlCHUR COLLAZOS, Iván.

2006 "García Márquez: con cara de palo", AFESE, n 46, disponible en: http://.afese.com/img/revista46/caradepalo.pdf

YAPKO, Michel.

2008 Tratado de hipnosis clínica. Madrid: Ediciones Palmyra 